\title{
Correction to: Remarkable response to roxadustat in a case of anti-erythropoietin antibody-mediated pure red cell aplasia
}

Ke Wan ${ }^{1} \cdot$ Yafei Yin ${ }^{2} \cdot$ Zimian Luo $^{2} \cdot$ Jianzhao Cheng $^{1}$

Published online: 16 October 2020

(C) Springer-Verlag GmbH Germany, part of Springer Nature 2020

Correction to: Annals of Hematology. https://doi.org/10.1007/s00277-020-04269-y

The article "Remarkable response to roxadustat in a case of anti-erythropoietin antibody-mediated pure red cell aplasia", written by Ke Wan, Yafei Yin, Zimian Luo and Jianzhao Cheng, was originally published online on September 17, 2020 with Open Access under a Creative Commons Attribution (CC BY) license 4.0. With the authors' decision to cancel Open Access the copyright of the article changed on October 2020 to $\odot$ Springer-Verlag GmbH Germany, part of Springer Nature 2020 with all rights reserved.

The original article has been corrected.

Publisher's note Springer Nature remains neutral with regard to jurisdictional claims in published maps and institutional affiliations.

The online version of the original article can be found at https://doi.org/ 10.1007/s00277-020-04269-y

Yafei Yin

sunlight2235@126.com

1 Department of Nephrology, Xiangtan Central hospital, Xiangtan City, Hunan Province, China

2 Department of Hematology, Xiangtan Central hospital, Xiangtan City 411100, Hunan Province, China 